\title{
Preparation of thermosensitive diblock copolymers consisting of MPEG and polyesters
}

\author{
Moon Suk Kim ${ }^{1}$, Hoon Hyun ${ }^{1,2}$, Gilson Khang ${ }^{2}$, Hai Bang Lee ${ }^{1 *}$ \\ ${ }^{1}$ Medicinal Science Division, Korea Research Institute of Chemical Technology, P.O. Box 107, \\ Yuseong, Daejeon 305-600, Korea \\ ${ }^{2}$ Department of Polymer/Nano Science and Technology, Chonbuk National University, 664-14, \\ Duckjin, Jeonju 561-756, Korea
}

Tel: 82-42-860-7220, Fax: 82-42-860-7228

e-mail: hblee@ krict.re.kr

\section{Experimental}

\section{Materials}

MPEG (Aldrich, number-average molecular weight $\left(M_{\mathrm{n}}\right) \approx 750$ ) and $\mathrm{HCl}$ (Aldrich; $1.0 \mathrm{M}$ solution in diethyl ether) were used as received. $\varepsilon$-Caprolactone (CL) was distilled over $\mathrm{CaH}_{2}$ under reduced pressure. L-Lactide (LA, Boehringer Ingelheim, Germany) was recrystallized in ethyl acetate two times. Trimethylene carbontate (TMC, Boehringer Ingelheim, Germany) was recrystallized in xylene. 1,4Dioxane-2-one (DO, Metabio, Korea) was used as received. $\mathrm{CH}_{2} \mathrm{Cl}_{2}$ was distilled sequentially from $\mathrm{CaCl}_{2}$ and $\mathrm{CaH}_{2}$ under nitrogen before use.

\section{Characterization}

${ }^{1} \mathrm{H}$ NMR spectra were measured using a Bruker $300 \mathrm{MHz}$ instrument with $\mathrm{CDCl}_{3}$ in the presence of TMS as internal standard. Molecular weight distributions of MPEG-PCL diblock copolymers were 
measured by a Futects At-3000 GPC system (Shodex RI-71 detector) using two columns (Shodex K802 and Shodex Asahipak GF-510). $\mathrm{CHCl}_{3}$ was used as the eluent at a flow rate of $0.6 \mathrm{~mL} / \mathrm{min}$. The crystallinity of the diblock copolymers was measured by X-ray diffraction (XRD; D/MAX-III B, Rigaku, Japan). A Ni filter at $35 \mathrm{kV}$ and $15 \mathrm{~mA}$ generated the radiation. The samples were placed in a quartz sample holder and scanned from 0 to $60^{\circ}$ at a scanning rate of $5 \% \mathrm{~min}$. The degree of crystallinity was calculated as the ratio of the crystalline peak areas to the total area under the scattering curve. The glass transition temperature $\left(T_{\mathrm{g}}\right)$, heat of fusion $\left(\Delta H_{\mathrm{m}}\right)$, and melting temperature $\left(T_{\mathrm{m}}\right)$ were determined with differential scanning calorimetry (DSC; Q 1000, TA Instruments, United States) from -100 (or 4) to $150{ }^{\circ} \mathrm{C}$ (or $80^{\circ} \mathrm{C}$ ) at a heating rate of $5^{\circ} \mathrm{C} / \mathrm{min}$ under a nitrogen atmosphere.

\section{Synthesis of MPEG- $b$-PCL diblock copolymer}

All glasses were dried by heating in vacuum and handled under a dry nitrogen stream. The typical process for the polymerization to give MPEG-PCL with PCL molecular weight $\left(2400, \mathrm{E}_{17} \mathrm{C}_{24}\right)$ is as follows. MPEG $\left(M_{\mathrm{n}}=750\right)(1.5 \mathrm{~g}, 2 \mathrm{mmol})$ and toluene $(30 \mathrm{~mL})$ were introduced into a flask. The MPEG solution was distillated by azeotropic distillation to remove water. Toluene was then distilled off completely. $\mathrm{CH}_{2} \mathrm{Cl}_{2}(91 \mathrm{~mL})$ was added to MPEG, followed by the addition of CL (5.2 g, $\left.45.6 \mathrm{mmol}\right)$ using syringe. The polymerization was initiated by the addition of $1.0 \mathrm{M}$ solution of $\mathrm{HCl}$ in diethyl ether $(4 \mathrm{~mL}, 4 \mathrm{mmol})$ at $25{ }^{\circ} \mathrm{C}$. After $24 \mathrm{~h}$, the reaction mixture was poured into $n$-hexane to precipitate a polymer, which was separated from the supernatant by decantation. The obtained polymer was redissolved in $\mathrm{CH}_{2} \mathrm{Cl}_{2}$ and then filtered. The polymer solution was concentrated by rotary evaporator and dried in vacuum to give a colorless polymer of quantitative yield. The molecular weight of PCL segment in the diblock copolymer was determined by the intensity of terminal methoxy proton signal of MPEG at $\delta=3.38 \mathrm{ppm}$ and methylene proton signal of PCL at $\delta=2.31 \mathrm{ppm}$ in ${ }^{1} \mathrm{H}$ NMR spectroscopy.

\section{Synthesis of MPEG- $b$-(PCL-co-PTMC) and MPEG- $b$-(PCL-co-PDO) diblock copolymer}


MPEG- $b$-(PCL-co-PTMC) or MPEG- $b$-(PCL-co-PDO) was synthesized with TMC or DO (in designed molar ratios) in a manner similar to that used for MPEG-PCL.

\section{Synthesis of MPEG-b-(PCL-co-PLLA) diblock copolymer $\left(\mathrm{E}_{17} \mathrm{C}_{23} \mathrm{~L}_{1}\right)$}

$\operatorname{MPEG}\left(M_{\mathrm{n}}=750 \mathrm{~g} / \mathrm{mol}\right)(1.5 \mathrm{~g}, 2 \mathrm{mmol})$ and toluene $(80 \mathrm{~mL})$ were introduced into a flask. The MPEG solution was distillated by azeotropic distillation to remove water. Toluene was then distilled off to give $30 \mathrm{~mL}$ in final volume. CL (4.8 g, $42 \mathrm{mmol})$ and LA (0.25 g, $1.7 \mathrm{mmol})$ was added to MPEG solution at room temperature under nitrogen, followed by the addition of $2.4 \mathrm{~mL}$ of $0.1 \mathrm{M}$ solution of stannous octoate in dried toluene. The mixture was stirred at $110^{\circ} \mathrm{C}$ for $15 \mathrm{~h}$. A reaction mixture was poured into a mixture of $n$-hexane and ethyl ether $(\mathrm{v} / \mathrm{v}=4 / 1)$ to precipitate a polymer, which was separated from the supernatant by decantation. The obtained polymer was redissolved in $\mathrm{CH}_{2} \mathrm{Cl}_{2}$ and then filtered. The polymer solution was concentrated by rotary evaporator and dried in vacuo to give a colorless polymer. The molecular weight of the PCL and PLLA segment in the diblock copolymers was determined by the comparison of the intensity for the terminal methoxy proton signal of MPEG at $\delta=3.38$ ppm, methylene proton signal of PCL at $\delta=2.31 \mathrm{ppm}$ and methylene protons signals of PLLA at $\delta=5.15$ ppm, respectively, in ${ }^{1} \mathrm{H}$ NMR spectroscopy.

\section{Viscosity measurements}

The MPEG-polyester diblock copolymers were dissolved in 4-mL vials with deionized water to make various concentrations and were stored at $4{ }^{\circ} \mathrm{C}$. After $24 \mathrm{~h}$, the viscosity of the polymer solutions were measured by using a Brookfield Viscometer DV-III ultra with programmable Rheometer and circulating baths with programmable controller TC-502P. The viscosity was measured by using a Brookfield Viscometer DV-III ultra with programmable Rheometer and circulating baths with programmable controller TC-502P. The viscosity of polymer solutions was investigated by using T-F spindle at 0.1 rpm from 6 to $70^{\circ} \mathrm{C}$ in increments of $2{ }^{\circ} \mathrm{C}$. 

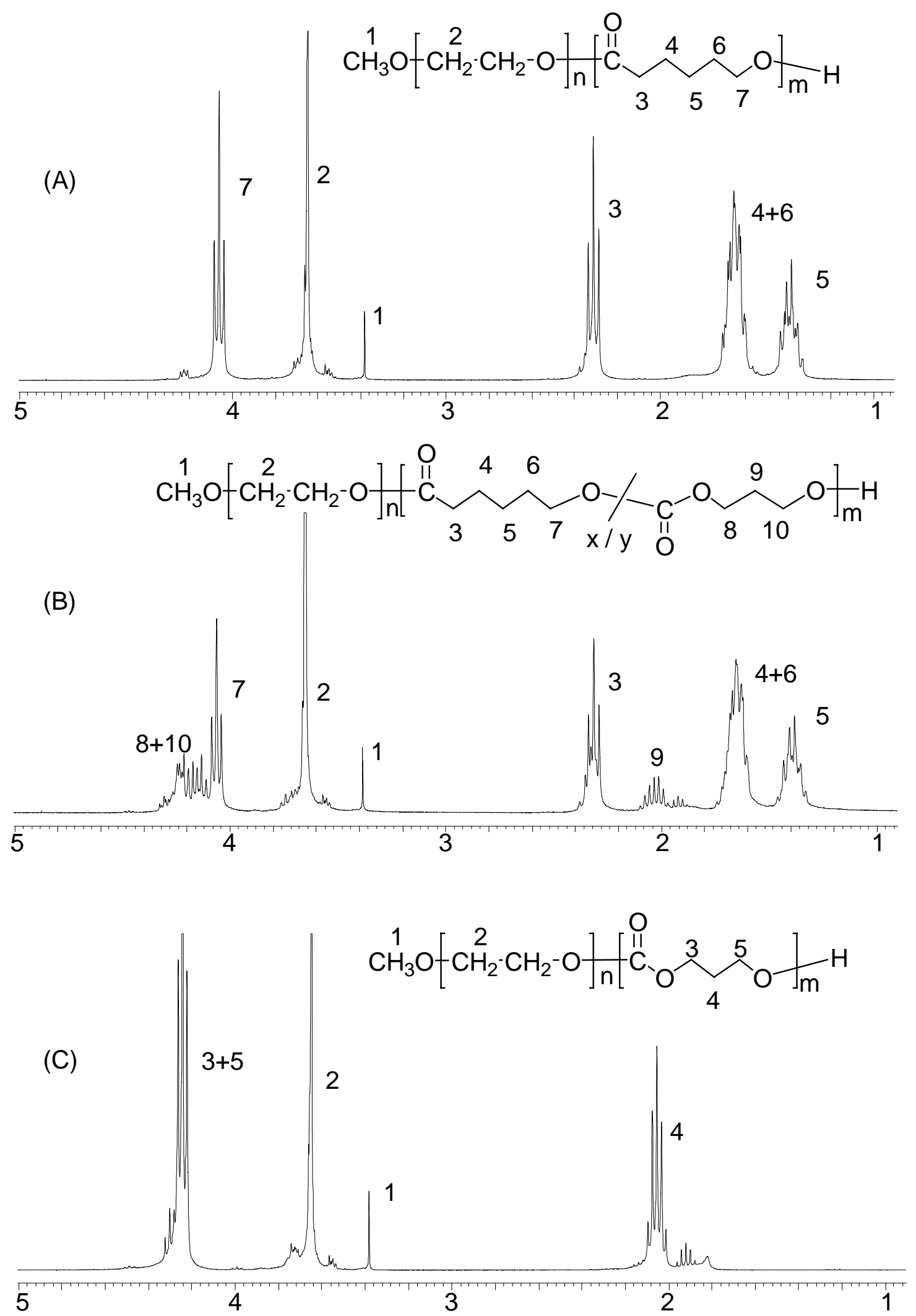

Figure S1. ${ }^{1} \mathrm{H}$ NMR spectra of $(\mathrm{A}) \mathrm{E}_{17} \mathrm{C}_{24}$, (B) $\mathrm{E}_{17} \mathrm{C}_{19} \mathrm{~T}_{5}$, and (C) $\mathrm{E}_{17} \mathrm{~T}_{24}$ in $\mathrm{CDCl}_{3}$. 

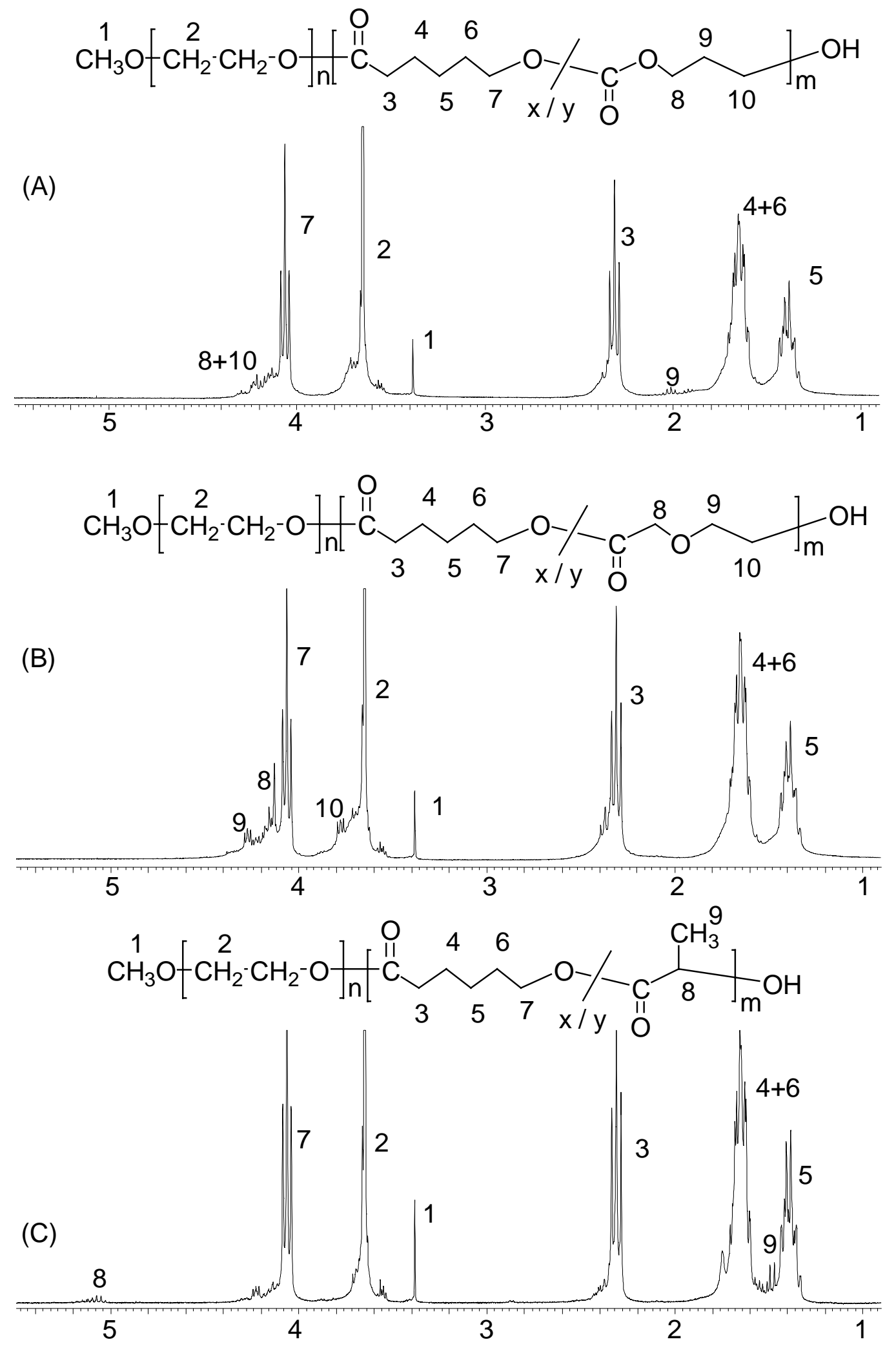

Figure S2. ${ }^{1} \mathrm{H}$ NMR spectra of (A) $\mathrm{E}_{17} \mathrm{C}_{23} \mathrm{~T}_{1}$, (B) $\mathrm{E}_{17} \mathrm{C}_{23} \mathrm{D}_{1}$, and (C) $\mathrm{E}_{17} \mathrm{C}_{23} \mathrm{~L}_{1}$ in $\mathrm{CDCl}_{3}$. 

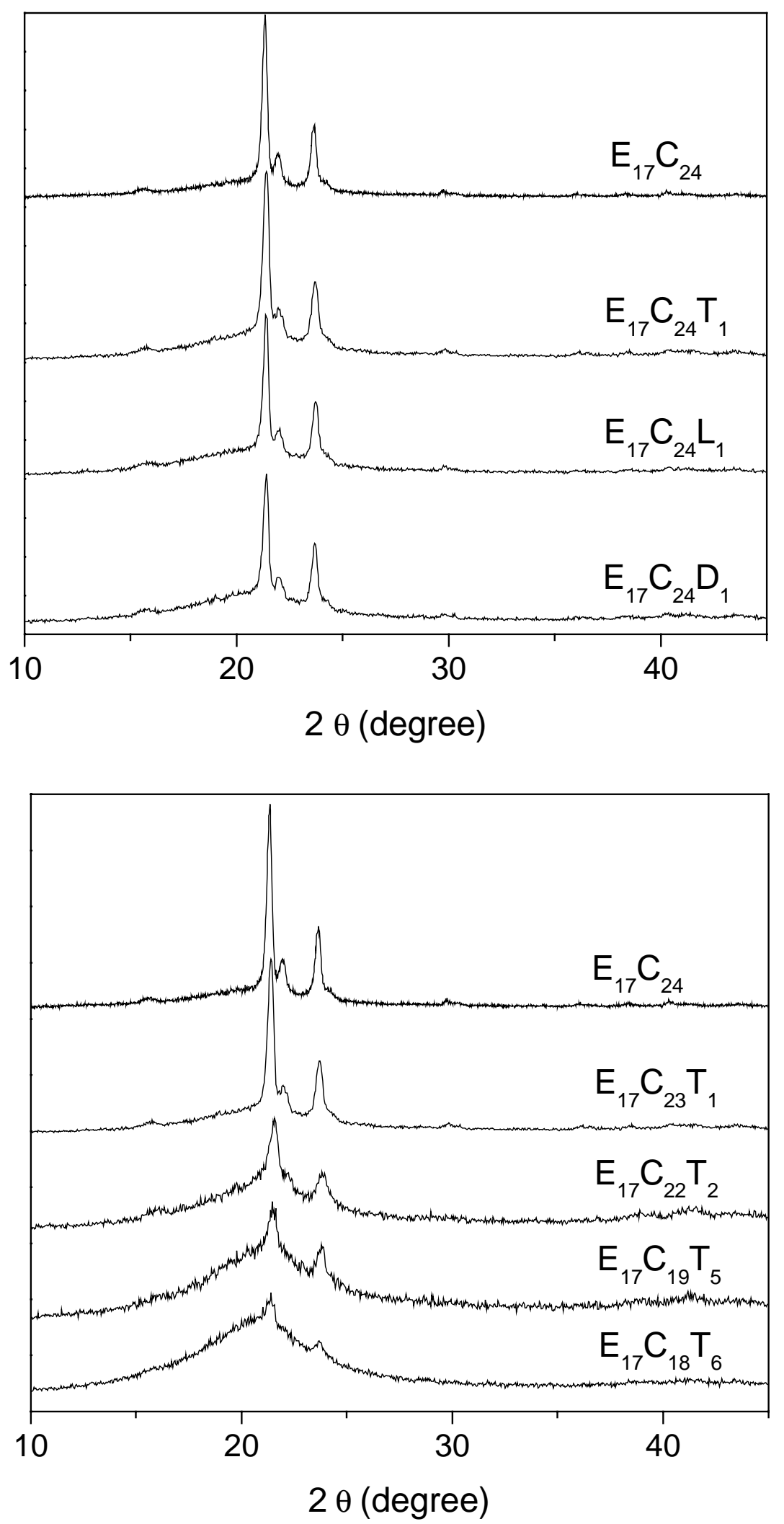

Figure S3. XRD profiles of diblock copolymers in bulk. 

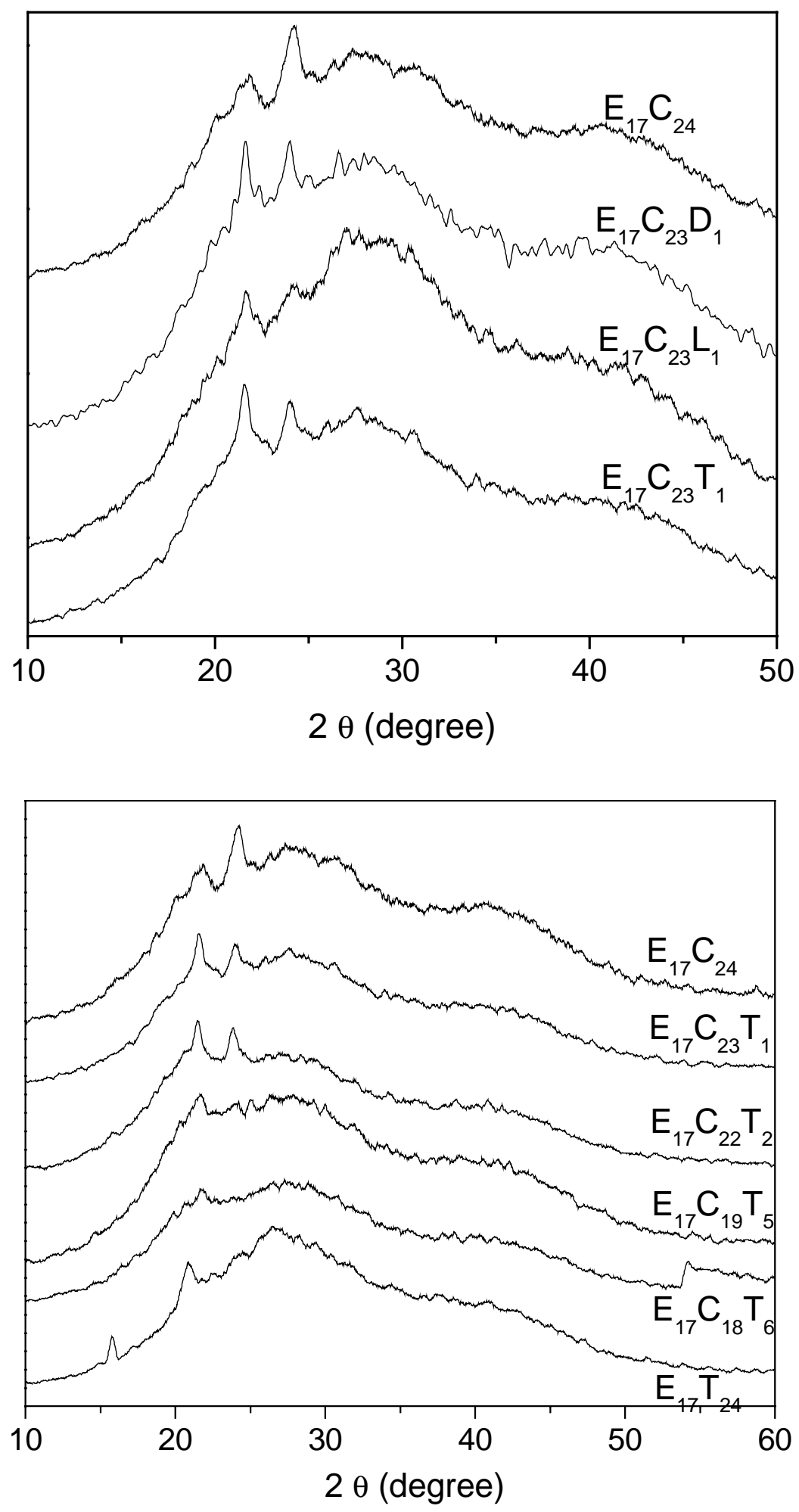

Figure S4. XRD profiles for $20 \mathrm{wt} \%$ aqueous solution of diblock copolymers. 
Table S1. The thermal properties ${ }^{\mathrm{a}}$ and degree of crystallinity for MPEG-polyester diblock copolymers in bulk state.

\begin{tabular}{|c|c|c|c|c|c|c|}
\hline \multirow{3}{*}{ No } & \multirow{3}{*}{$T_{\mathrm{g}}\left({ }^{\circ} \mathrm{C}\right)$} & \multicolumn{2}{|c|}{ MPEG block } & \multicolumn{2}{|c|}{ polyester block } & \multirow{3}{*}{$\chi_{c}^{b}$} \\
\hline & & $T_{\mathrm{m} \text { PEG }}$ & $\Delta \mathrm{H}_{\mathrm{m}}$ & $T_{\mathrm{m} \text { PCL }}$ & $\Delta \mathrm{H}_{\mathrm{m}}$ & \\
\hline & & $\left({ }^{\circ} \mathrm{C}\right)$ & $(\mathrm{J} / \mathrm{g})$ & $\left({ }^{\circ} \mathrm{C}\right)$ & $(\mathrm{J} / \mathrm{g})$ & \\
\hline $\mathrm{E}_{17} \mathrm{C}_{24}$ & -69.7 & 17.2 & 15.9 & 53.3 & 84.3 & 36.4 \\
\hline $\mathrm{E}_{17} \mathrm{C}_{23} \mathrm{~T}_{1}$ & -68.4 & 16.6 & 2.5 & 47.1 & 73.3 & 30.7 \\
\hline $\mathrm{E}_{17} \mathrm{C}_{23} \mathrm{D}_{1}$ & -66.7 & 16.1 & 15.6 & 42.3 & 60.7 & 26.9 \\
\hline $\mathrm{E}_{17} \mathrm{C}_{23} \mathrm{~L}_{1}$ & -67.3 & 13.7 & 15.7 & 46.3 & 67.6 & 27.1 \\
\hline $\mathrm{E}_{17} \mathrm{C}_{22} \mathrm{~T}_{2}$ & -65.9 & 22.2 & 10.7 & 43.1 & 49.4 & 22 \\
\hline $\mathrm{E}_{17} \mathrm{C}_{19} \mathrm{~T}_{5}$ & -63.3 & 20.5 & 22.8 & 35.5 & 26.1 & 18.3 \\
\hline $\mathrm{E}_{17} \mathrm{C}_{18} \mathrm{~T}_{6}$ & -62.3 & 17.4 & 29.4 & 33.1 & 16.4 & 15.2 \\
\hline $\mathrm{E}_{17} \mathrm{~T}_{24}$ & $-49.4(-9)$ & 34.5 & 40.1 & - & - & 38.7 \\
\hline
\end{tabular}

\footnotetext{
${ }^{\mathrm{a}}$ Measured by DSC.

${ }^{\mathrm{b}} \chi$ was calculated as the ratio of the crystalline peak areas to the total areas under the scattering curve.
} 
Table S2. The thermal properties for MPEG-polyester aqueous solution at 20wt $\%$ concentrations. ${ }^{\mathrm{a}}$

\begin{tabular}{cccc}
\hline & $\chi_{c}^{\mathrm{b}}$ & $T_{\mathrm{m}}$ & $\Delta \mathrm{H}_{\mathrm{m}}$ \\
& & $\left({ }^{\circ} \mathrm{C}\right)$ & $(\mathrm{J} / \mathrm{g})$ \\
\hline $\mathrm{E}_{17} \mathrm{C}_{24}$ & 7.2 & 47.8 & 13.3 \\
$\mathrm{E}_{17} \mathrm{C}_{23} \mathrm{~T}_{1}$ & 6.7 & 44.1 & 10.8 \\
$\mathrm{E}_{17} \mathrm{C}_{23} \mathrm{D}_{1}$ & 5.8 & 39.9 & 8.4 \\
$\mathrm{E}_{17} \mathrm{C}_{23} \mathrm{~L}_{1}$ & 6 & 42.8 & 10.1 \\
& & & \\
$\mathrm{E}_{17} \mathrm{C}_{22} \mathrm{~T}_{2}$ & 6.2 & 40.1 & 6.5 \\
$\mathrm{E}_{17} \mathrm{C}_{19} \mathrm{~T}_{5}$ & 5.4 & 32.7 & 4.5 \\
$\mathrm{E}_{17} \mathrm{C}_{18} \mathrm{~T}_{6}$ & 3.5 & 28.9 & 1.4 \\
$\mathrm{E}_{17} \mathrm{~T}_{24}$ & 1.6 & - & - \\
\hline
\end{tabular}

${ }^{\mathrm{a}}$ Measured by DSC.

${ }^{\mathrm{b}} \chi$ was calculated as the ratio of the crystalline peak areas to the total areas under the scattering curve. 